\title{
AGRIBISNIS TANAMAN STROBERI DI DESA RURUKAN KECAMATAN TOMOHON TIMUR
}

\section{AGRIBUSINESS OF STRAWBERRIES CROP IN RURUKAN VILLAGE OF EAST TOMOHON DISTRICT}

\author{
Denny Saroinsong1), V.V.J. Panelewen2), O.E.H. Laoh'), dan C.B.D. Pakasi3) \\ 1)Fakultas Perikanan dan IImu Kelautan Unsrat Manado \\ 2)Fakultas Peternakan Unsrat Manado \\ 3)Fakultas Pertanian Unsrat Manado
}

\begin{abstract}
Strawbery is one of the most important fruits commodity in the world, especially for the subtropics countries. Although the strawberry is not a native to Indonesia, but its development which is patterned by the agribussiness and agro-industries can be categorized as one of the income sources in the agricultural sector. Despite the development of strawberries in Indonesia continues to increase, but when compared with overseas, the strawberry business in Indonesia has not optimally performed. The purposes of this study are to assess and to explain the strawberry crop agri-businesses in the Rurukan Village of East Tomohon District. The results showed that in general, the farming cultivation of strawberry, consisted of: land cultivation, the nursery, and media plant cultivation. It was very important to manage the successful development by the farmers, i.e.: the technique of strawberry planting.
\end{abstract}

Keywords : agribusiness, crop strawberry

\begin{abstract}
ABSTRAK
Pelaksanaan sistem penempatan yang benar dimaksudkan agar stroberi menjadi salah satu komoditas buah-buahan yang penting di dunia, terutama untuk negara-negara beriklim subtropis. Di Indonesia, walaupun stroberi bukan merupakan tanaman asli Indonesia, namun pengembangan komoditas ini yang berpola agribisnis dan agroindustri dapat dikategorikan sebagai salah satu sumber pendapatan dalam sektor pertanian. Meskipun perkembangan stroberi di Indonesia terus mengalami peningkatan, namun bila dibandingkan dengan luar negeri, usaha stroberi di Indonesia belum dilakukan secara optimal. Tujuan penelitian ini untuk mengkaji serta menjelaskan agribisnis usaha tanaman stroberi di Desa Rurukan Kecamatan Tomohon Timur. Hasil penelitian menunjukkan bahwa usahatani yang dilakukan dalam budidaya tanaman stroberi secara umum meliputi : mengelolah lahan, pembibitan, pengolahan media tanam. Hal yang sangat penting untuk selalu dilakukan petani agar pengembangan tanaman stroberinya berhasil yaitu teknik penanaman stroberi.

Kata kunci : agribisnis, tanaman stroberi
\end{abstract}

Eugenia Volume 18 No. 3 Desember 2012 


\section{PENDAHULUAN}

Tanaman stroberi merupakan tanaman buah berupa herba yang ditemukan pertama kali di Chili, Amerika. Salah satu spesies tanaman stroberi yaitu Fragaria choiloensis $L$. menyebar ke berbagai negara Amerika, Eropa dan Asia. Selanjutnya spesies lain, yaitu Fragaria vesca L. lebih menyebar luas dibandingkan spesies lainnya. Jenis stroberi ini pula yang pertama kali masuk ke Indonesia. Stroberi yang kita temukan di pasar swalayan ialah hibrida yang dihasilkan dari persilangan Fragaria virgiana L. var Duchesne asal Amerika Utara dengan Fragaria Chiloensis L. var Duchesne asal Chili. Persilangan itu menghasilkan hybrid yang merupakan stroberi moderen (komersil) Fragaria $x$ annanassa var Duchesne (Darwis, 2007).

Seiring perkembangan ilmu dan teknologi pertanian yang semakin maju, kini stroberi mendapat perhatian pengembangannya di daerah beriklim tropis. Di Indonesia, walaupun stroberi bukan merupakan tanaman asli Indonesia, namun pengembangan komoditas ini yang berpola agribisnis dan agroindustri dapat dikategorikan sebagai salah satu sumber pendapatan dalam sektor pertanian. Stroberi ternyata dapat tumbuh dan berproduksi dengan baik dalam kondisi iklim seperti di Indonesia (Budiman dan Saraswati, 2008).

Hal ini terlihat dari beberapa perkebunan stroberi yang terdapat di Lembang, Ciwidey (Bandung), Cipanas (Cianjur), Tawangmangu (Karanganyar), Batu (Malang), Tabanan, Bedugul (Bali), Karangmulya (Garut), dan Sawangan (Magelang) yang dikenal sebagai sentra stroberi di Indonesia. Banyaknya industri pengolahan yang memanfaatkan stroberi sebagai bahan baku serta pasar yang membutuhkan stroberi untuk konsumsi segar juga turut mempengaruhi potensi untuk pengembangan budidaya stroberi.

Meskipun perkembangan stroberi di Indonesia terus mengalami peningkatan, namun bila dibandingkan dengan luar negeri, usaha stroberi di Indonesia belum dilakukan secara optimal. Petani kebanyakan masih menggunakan penerapan budidaya yang sifatnya konvensional.
Kelemahan atas pengolahan lahan yang tidak terpadu bisa menimbulkan kerentanan tanaman terhadap hama dan penyakit serta dapat mengurangi kuantitas dan kualitas produksi. Selain itu, terkadang dengan cara yang konvensional biaya produksi yang digunakan tidak sebanding dengan keuntungan yang diperoleh (Kurnia, 2005).

Di Sulawesi Utara terdapat salah satu desa yang sedang giat-giatnya mengembangkan usaha stroberi yaitu Desa Rurukan. Budidaya stroberi yang dilakukan oleh petani di desa tersebut masih bersifat konvensional dan masih dalam skala kecil. Ada kalanya petani tidak begitu memperhatikan teknik budidaya seperti pemupukan dan pemeliharaan, teknologi juga masih kurang diterapkan oleh petani, sehingga kualitas dan kuantitas produksi yang dihasilkan masih tergolong belum maksimal.

Berkenaan dengan pengembangan stroberi, maka perlu dilakukan penelitian ini dengan tujuan untuk mengkaji agribisnis tanaman stroberi di Desa Rurukan Kecamatan Tomohon Timur.

\section{METODE PENELITIAN}

Penelitian dilaksanakan di Desa Rurukan Kecamatan Tomohon Timur Kota Tomohon selama 4 bulan, yang dilakukan berdasarkan Metode Kualitiatif. Penelitian kualitatif merupakan penelitian yang mampu memberikan deskripsi secara detail dan analisa mengenai kualitas atau isi dari suatu pengalaman manusia. Hal ini membuat penelitian tersebut mampu menggambarkan suatu kehidupan dari sisi yang berbeda berdasarkan sudut pandang dari setiap orang yang mengamatinya (Marvasti, 2004). Penelitian kualitatif ini merupakan bentuk penelitian yang secara aktif melibatkan peneliti untuk mengumpulkan dan menggunakan data empiris dengan berbagai cara dan metode (Denzin and Lincoln, 2003).

Sumber penelitian dalam penelitian ialah subyek darimana data diperoleh. Menurut Arikunto (2006), berdasarkan alat pengumpulan data, maka sumber data dapat dibedakan menjadi dua. Jika yang digunakan kuisioner maka sumberdatanya disebut responden, dan jika yang digunakan 
observasi maka sumber datanya berupa benda, gerak atau proses sesuatu. Menurut Moleong (2000), yang menjadi sumber data utama dalam penelitian kualitatif ialah kata-kata dan tindakan.

Informan adalah orang yang berada pada lingkup penelitian, artinya merupakan orang yang dapat memberikan informasi tentang situasi dan kondisi latar penelitian. Menurut Soemanto (1995) dalam penelitian dengan pendekatan deskriptif penentuan jumlah informan tidak ada ukuran mutlak. Informan dipilih dengan tujuan mendeskripsikan suatu gejala sosial atau masalah sosial tertentu berdasarkan pertimbangan tertentu sehingga disebut sampling bertujuan (purposive sampling). Informan dalam penelitian ini yaitu pemerintah sebanyak 1 informan, tokoh masyarakat sebanyak 2 informan dan petani yang ada di Desa Rurukan sebanyak 17 informan dengan jumlah keseluruhan 20 informan.

Data diperoleh dengan menggunakan tiga cara (Sutanto dan Sutinah, 2006), yaitu : pertama yaitu wawancara mendalam dan terbuka, kedua ialah observasi langsung, dengan observasi langsung peneliti ingin melihat lebih rinci tentang kegiatan, perilaku, tindakan orang-orang, serta juga keseluruhan kemungkinan interaksi interpersonal, dan proses penataan yang merupakan bagian dari pengalaman manusia yang dapat diamati, ketiga yaitu penelaahan terhadap dokumen tertulis.

Adapun fokus penelitian yaitu: pengembangan usaha tanaman stroberi di Desa Rurukan Kecamatan Tomohon Timur, yang dirinci sebagai berikut : usahatani tanaman stroberi, tahapan pasca panen yang dilakukan petani pengembang tanaman stroberi, keuntungan yang didapat petani pengembang tanaman stroberi.

Miles and Huberman (1984) mengemukakan bahwa, aktivitas dalam analisis data kualitatif dilakukan secara interaktif dan berlangsung secara terus-menerus sampai tuntas, sehingga datanya jenuh. Ukuran kejenuhan data ditandai dengan tidak diperolehnya lagi data atau informasi baru. Aktivitas dalam analisis meliputi reduksi data (data reduction), penyajian data (data display), serta penarikan kesimpulan dan verifikasi (conclusion drawing/verification).

\section{HASIL DAN PEMBAHASAN}

\section{Usahatani yang Dilakukan dalam Budidaya Tanaman Stroberi}

Hasil penelitian menunjukkan bahwa petani sudah cukup maskimal dalam membudidayakan tanaman stroberinya. Menurut informan, usahatani tanaman stroberi merupakan salah satu kegiatan yang saat ini banyak dilakukan oleh petani-petani yang ada di Desa Rurukan. Usahatani tanaman stroberi oleh petani juga mendapat respon baik dari pihak pemerintah maupun pihak swasta, hal ini nampak dari pemberian bantuan-bantuan pendampingan kepada para petani.

Di dalam usahatani tanaman stroberi, menurut salah satu informan faktor bibit sangatlah penting, karena tanpa bibit atau benih yang baik, maka hasil buah stroberi tidak akan maksimal. Kebutuhan bibit per satuan luas lahan ditentukan oleh varietas tanaman stroberi dan jarak tanam yang digunakan. Jumlah bibit yang ditanam diperkirakan berkisar antara 40.000-83.333 bibit per hektar. Bibit yang digunakan dapat berasal dari hasil perbanyakan tanaman secara generatif (biji) dan vegetatif berupa anakan atau stolon. Hal terpenting yang harus disiapkan dalam penyiapan bibit ialah pemilihan bibit yang bermutu prima, berasal dari varietas unggul, dan cocok dengan kondisi agroekologi setempat, sebulan sebelum tanam sebaiknya bibit diadaptasikan dulu di lokasi kebun.

Informan lainnya berpendapat bahwa, disamping memilih bibit buah stroberi yang akan ditanam, hal terpenting juga yang harus dilakukan terlebih dahulu yaitu menyiapkan lahan yang akan dijadikan sebagai tempat menanam buah stroberi. Lahan kebun tanaman stroberi yang disiapkan biasanya dalam bentuk bedengan-bedengan atau guludan tanpa mulsa plastik ataupun sistem bermulsa plastik. Lahan kebun tanaman stroberi diolah secara sempurna/baik.

Menurut informan, waktu pengolahan tanah yang paling baik ialah pada awal musim hujan agar ketersediaan air memadai, namun pada daerah yang sumber airnya cukup, pengolahan tanah dapat dilakukan setiap saat. Menurut informan yang berprofesi sebagai petani stroberi, 
dia memiliki lahan seluas $1 / 4$ ha, dan dalam usahatani tanaman stroberi informan tersebut memilih waktu penanamannya pada awal musim hujan karena kebetulan lokasi/kebun miliknya memiliki pasokan air yang tergolong kurang.

Informan lainnya berpendapat bahwa untuk menghasilkan tanaman stroberi yang memiliki kwalitas yang baik haruslah dalam proses usahatani tanaman stroberi dilakukan pemeliharaan tanaman dengan memperhatikan hal-hal sebagai berikut : penyiraman (pengairan), penyulaman, pemulsaan jerami kering, penyiangan, pemupukan susulan, pemangkasan, perlindungan (proteksi) tanaman.

Menurut informan, untuk tetap dapat menghasilkan stroberi yang berkwalitas, tanaman stroberi yang berumur lebih dari 2 tahun sudah saatnya diremajakan atau diganti dengan bibit yang baru. Tanda-tanda tanaman stroberi yang sudah harus diremajakan yaitu tanaman tumbuk kerdil, bunga rontok, dan buah yang terbentuk berukuran kecil-kecil serta berjumlah sangat sedikit. Peremajaan pada prinsipnya ialah membongkar (eradikasi) seluruh tanaman stroberi yang telah berumur lebih dari dua tahun dan tanaman yang tidak produktif berbuah, kemudian tanahnya diolah menjadi lahan bukaan baru, selanjutnya ditanami bibit tanaman stroberi yang baru pula.

Informan lainnya berpendapat bahwa ada petani-petani yang masih sulit untuk mengembangkan tanaman stroberinya. Salah satu faktor penyebabnya yaitu karena mereka belum mendapatkan bantuan dana baik itu dari pihak pemerintah maupun dari pihak swasta. Untuk pengembangan tanaman stroberi dibutuhkan biaya yang tidak sedikit, maka dari itu terkadang para petani juga meminjam uang dari rentenir untuk dapat mengeIolah lahan petanian stroberi milik mereka. Selain masalah biaya juga keterbatasan alat-alat bantu guna pengolahan lahan dan pemeliharaan tanaman stroberi. Umumnya petani hanya mengelolah tanaman mereka secara tradisional, hal ini berdampak pada hasil panen buah stroberi yang dirasakan belum maksimal.

\section{Tahapan Pasca Panen Buah Stroberi}

Hasil penelitian menunjukkan bahwa petani stroberi berusaha semaksimal mungkin agar hasil panen buah stroberi tetap segar sampai akan dipasarkan dan sampai di tangan konsumen. Menurut informan, buah stroberi termasuk tanaman ringkih, sehingga pada saat pascapanen diperlukan cara penanganan yang memadai untuk mempertahankan kualitas, daya simpan, dan daya gunanya. Penanganan pascapanen ialah tahap-tahap kegiatan usahatani sejak pemanenan hingga siap dipasarkan atau dikonsumsi. Kegiatan pokok penanganan pasca panen buah stroberi yang bertujuan untuk konsumsi segar ialah: pengumpulan hasil, pengangkutan dan pencucian, sortasi dan klasifikasi.

Di pasaran terdapat tiga kelas kualitas buah stroberi yang tertera Tabel 1 .

Persyaratan umum dari buah stroberi yang akan dipasarkan yaitu : buah utuh, sehat, bebas dari hama dan penyakit, partikel tanah, pestisida, serta kotoran lain.

Tabel 1. Kualitas Buah Stroberi

(Table 1. The Quality of Strawberry)

\begin{tabular}{cll}
\hline No. Kualitas buah & & \multicolumn{1}{c}{ Karakteristik } \\
\hline 1. Kelas ekstra & a) Buah berukuran antara 20-30 mm atau tergantung varietas \\
& b) Buah seragam dalam ukuran, warna dan tingkat kematangannya \\
2. Kelas I & a) Buah berukuran antara 15-25 mm, tergantung varietas \\
3. Kelas II & b) Bentuk dan warna buah varietas \\
& a) Tidak ada batasan ukuran minimum buah \\
& b) Sisa seleksi dari kualitas kelas ekstra dan kelas I, tetapa keadaan \\
&
\end{tabular}


Menurut informan, sebelum dipasarkan buah stroberi lebih dulu dikemas. Kegiatan-kegiatan pokok pengemasan meliputi: 1) siapkan kotak plastik bening (transparan) berkapasitas $1 / 4-1 \mathrm{~kg}$, tergantung dari permintaan pasar; 2) masukkan buah stroberi yang telah dipanen tersebut secara berhati-hati ke dalam kotak plastik hingga penuh; 3) tutup permukaan kotak plastik berisi buah stroberi dengan lebar plastik polietilene; 4) pasang label serta etiket yang dapat menarik perhatian konsumen.

Tata cara pengepakan dan pengangkutan buah stroberi yang telah dikemas ialah sebagai berikut : 1) masukkan kemasan buah stroberi tadi ke dalam dos karton atau keranjang secara bersusun, selanjutnya ditata satu per satu dalam mobil pengangkutan; 2) angkut buah stroberi yang telah ditata ke dalam dos karton ke tempat-tempat penjualan (pemasaran).

Tata cara penyimpanan ialah sebagai berikut : 1) bongkar semua wadah (kemasan) buah stroberi dari mobil angkutan; 2) simpan kemasan buah stroberi tersebut pada rak-rak penyimpanan atau lemari pendingin bersuhu antara $0^{\circ} \mathrm{C}-1^{\circ} \mathrm{C}$.

Menurut informan, tujuan utama dari pengolahan buah stroberi pasca dipanen ialah untuk meningkatkan keawetan buah sehingga baik dikonsumsi. Selain itu, pengolahan buah stroberi dapat meningkatkan nilai tambah serta dalam penganekaragaman (diversifikasi) bahan pangan. Pengolahan buah stroberi dapat dilakukan secara sederhana pada skala industri rumah tangga penduduk. Aneka produk olahan buah stroberi antara lain jam, jelly, dodol, dan aneka produk olahan lainnya.

Menurut informan, buah stroberi biasanya dipasarkan di supermarket-supermarket yang ada di daerah Tomohon dan di Kota Manado, juga di restoran dan hotel yang ada di Kota Tomohon dan sekitarnya, akan tetapi ada juga konsumen yang datang langsung ke kebun stroberi untuk membeli buah stroberi, karena menurut mereka buah stroberi yang baru dipetik rasanya lain, lebih segar dan lebih enak. Hal ini banyak dimanfaatkan oleh para petani stroberi menjadikan kebun stroberi miliknya bukan hanya sekedar kebuh stroberi saja tetapi sudah dijadikan tempat wisata.

\section{Keuntungan Petani Pengembang Tanaman Stroberi}

Hasil penelitian menunjukkan bahwa keuntungan dari petani pengembang tanaman stroberi yaitu mengalami peningkatan penghasilan sejak petani mulai mengembangkan tanaman stroberi secara serius. Menurut informan, dengan adanya usahatani tanaman stroberi di Desa Rurukan maka berangsur-angsur kehidupan sosial ekonomi dari para petani dan para pekerja mulai mengalami peningkatan ke arah yang lebih baik. Seorang informan berpendapat bahwa, dahulu saat masih menjadi petani sayuran, pendapatannya belum bisa mencukupi semua kebutuhan hidup keluarga, akan tetapi pada saat sudah beralih menjadi petani stroberi, kehidupan keluarganya semakin meningkat, dengan demikian maka status sosial dari keluarga di dalam bermasyarakat juga meningkat.

Informan lainnya memberikan contoh bagaimana keuntungan berupa perubahan keadaan sosial ekonomi menjadi lebih baik setelah menjadi petani stroberi, dahulunya rumah mereka masih terbuat dari kayu yang sudah lapuk dimakan usia, akan tetapi setelah mereka berhasil dalam usahatani tanaman stroberi, mereka sudah mampu untuk membuat rumah semi permanen dan sudah lebih layak untuk ditempati, dan bukan itu saja, mereka juga mampu untuk menyekolahkan anak-anaknya ke jenjang yang lebih tinggi.

Menurut informan, dengan adanya keuntungan berupa penghasilan yang meningkat sehingga semakin baiknya keadaan sosial ekonomi mereka, maka umumnya petani menjadi lebih bersemangat lagi untuk mengembangkan tanaman stroberi dan menjadikan tanaman stroberi sebagai tanaman prioritas mereka untuk dikembangkan, namun mereka tetap juga menanam sayuran karena menanam sayuran sudah lama dilakukan oleh petani.

\section{KESIMPULAN}

Berdasarkan hasil penelitian dan pembahasan yang diperoleh, maka dapat disimpulkan bahwa secara umum agribisnis usaha tanaman stroberi Di Desa Rurukan Kecamatan Tomohon 
Timur sudah cukup maskimal, hal ini dibuktikan dengan: Usahatani yang dilakukan dalam budidaya tanaman stroberi secara umum yaitu mengelolah lahan, pembibitan, pengolahan media tanam. Hal yang sangat penting untuk selalu dilakukan petani agar pengembangan tanaman stroberinya berhasil, yaitu: teknik penanaman stroberi. Setelah stroberi tumbuh, hal yang selanjut-nya wajib dilakukan yaitu pemeliharaan tanaman. Pemeliharaan tanaman terdiri dari: penyulaman, penyiangan, perempelan/ pemangkasan, pemupukan, pengairan dan penyiraman serta pemasangan mulsa kering. Di dalam pengembangan tanaman stroberi ada sebagian petani yang mengalami permasalahan kurangnya modal, yang berdampak pada kurang maksimalnya pengembangan tanaman stroberi. Tahapan pascapanen yang dilakukan petani yaitu: 1) pengumpulan; 2) penyortiran dan penggolongan; 3) pengemasan dan penyimpanan. Pengolahan buah stroberi biasanya dilakukan secara sederhana pada skala industri rumah tangga penduduk. Aneka produk olahan buah stroberi yang dibuat petani masih terbatas, antara lain selai dan dodol. Keuntungan petani pengembang tanaman stroberi di Desa Rurukan umumnya mengalami peningkatan pendapatan, yang berdampak pada meningkatnya kondisi ekonomi. Peningkatan di bidang sosial terlihat dari luasnya hubungan sosial ekonomi penduduk, kemajuan pendidikan baik petani maupun anggota keluarganya, organisasi juga wawasan dari petani.

\section{DAFTAR PUSTAKA}

Arikunto, S. 2006. Prosedur Penelitian Suatu Pendekatan Praktik. Jakarta : Rineka Cipta.

Budiman, S. dan D. Saraswati. 2008. Berkebun Stroberi Secara Komersial. Penebar Swadaya. Jakarta.

Darwis, V. 2007. Budidaya, Analisis Usahatani, Dan Kemitraan Stroberi Tabanan Bali. Pusat Analisasi Sosial Ekonomi dan Kebijakan Pertanian. Jakarta.

Denzin, N. K. and Y.S. Lincoln. 2005. The Sage Handbook of Qualitative Research. Third Edition. Thousand Oaks, California: Sage Publications Inc.

Kurnia, A. 2005. Petunjuk Praktis Budi Daya Stroberi. Agro Medika Pustaka : Jakarta.

Marvasti, A. B. 2004. Qualitative Research in Sociology. Sage Publications: London.

Miles, M.B. and A.M. Huberman. 1984. Qualitative Data Analysis: An Expanded Sourcebook. New York: SAGE Publications.

Moleong, L. 2000. Metodologi Penelitian Kualitatif. PT. Remaja Rosdakarya : Bandung.

Soemanto. 1995. Metode-Metode Penelitian. Gramedia. Jakarta.

Sutanto, B. dan Sutinah. 2006. Metode Penelitian Sosial. Kencana. Jakarta. 
